\title{
Diarrhea caused by shiga-toxigenic Escherichia coli, other pathogens and HUS. Effects of bismuth hydroxide gel
}

\begin{abstract}
Diarrheal diseases are the second leading cause of death in children under 5 years of age Their symptoms are caused by viruses, bacteria or parasites that reach the digestive tract. In Argentina the bacterial etiology is the most common. Its most common etiology is related to Shigella or enter hemorrhagic Escherichia coli producing Shiga toxin (Stx), which are responsible for endemoepidemic hemolytic uremic syndrome (HUS) in Argentina.

Recent studies have analyzed and clarified some of the mechanisms involved in the therapeutic effects of bismuth hydroxide gel (BHG). The latest research focused on identifying its effects on the growth and pathogen city factors of various microorganisms responsible for gastrointestinal infections, including human Rotavirus Wa, E. coli and Shigella, as well as those strains that produce Stx and Campylobacter jejuni. The research identified the ability of BHG to block the spread of genes that encode Stx mediated by lambdoid phages and its inhibitory action on Stx in the human colon. It reports on advances in knowledge about the effect of BHG on enterotoxigenic E. coli in the bovine reservoir and its influence on limiting the potential contamination of meat and its derivatives. The reviewed research clarifies the mechanisms involved in the therapeutic action of BHG. It affected three events intervening in the process of bacterial adhesion and colonization: fimbriation, mobility and surface hydrophobicity. It inhibits the replication of the phage transmitting the Stx gene and the cytotoxic action of Stx2 in the human colon.
\end{abstract}

Volume 6 Issue I - 2017

\author{
Viviana Altinier,' Graciela Martín ${ }^{2}$ \\ 'Pediatric Specialists, Associate Director. Chair, Department of \\ Pediatric Clinical hospitalization, Hospital de Niños Sor María \\ Ludovica. República Argentina \\ ${ }^{2}$ Pediatric Gastroenterologists, Ex chair, Department of Pediatric \\ Gastroenterology, Hospital Pediátrico Dr.A. L. Castelan, \\ República Argentina
}

\author{
Correspondence: Graciela Martin, MD, Pediatric \\ Gastroenterologists, Ex chair, Department of Pediatric \\ Gastroenterology, Hospital Pediátrico Dr.A. L. Castelan, \\ Resistencia Chaco, República Argentina, \\ Email gracielamartin987@gmail.com
}

Received: December 03, 2016 | Published: January 5, 2017

\section{Introduction}

Childhood diarrhea continues to be a prevailing illness and therefore, advancements in new treatments are particularly wellvalued. This article is a review on various Argentinian research works on the role of bismuth hydroxide gel (BHG) with respect to the main gastrointestinal pathogens, highlighting the inhibition and blockage of the spreading of genes that encode Shiga toxin (Stx) and its inhibitory action on Stx in the human colon. It also provides information on the advancements made in our knowledge about BHG action on enterotoxigenic Escherichia coli, its bovine reservoir and its influence in limiting the possible contamination of beef and its by-products. Acute diarrhea in children is defined as the increased frequency, flow, and volume of fecal matter in relation to the normal habit of the child, whose duration is less than two weeks.

It is the second leading cause of preventable infant mortality in children under 5 years of age. The lack of drinking water and adequate sanitation are the main culprits in low-income countries. ${ }^{1}$ It is transmitted through contaminated food, water, or direct contact with the improperly sanitized hands of those carrying it.

Their symptoms are caused by viruses, bacteria, parasites or fungi that reach the digestive tract. The viral etiology (Rotavirus) is common during the fall in children under two years of age, which has a sudden onset with vomiting and fever that precedes the onset of diarrheal disease. It is usually self-limited in 5 to 7 days, and sometimes produces poor transient absorption caused by Cytotoxicity in the villi of the small intestine.

The bacterial etiology is more common in summer in older children. The presence of fever and diarrhea with mucus, blood and/or pus can provide good guidance. The most common germs are related to Shigella or enteropathogenic, enteroinvasive, enterotoxigenic and enter hemorrhagic E. coli producing Shiga toxin (Stx), Campylobacter jejuni and Salmonella. Those involving enter hemorrhagic Stxproducing Escherichia coli can generate hemolytic uremic syndrome (HUS).

HUS is a clinical condition usually preceded by diarrhea characterized by microangiopathic hemolytic anemia, thrombocytopenia and varying degrees of impairment of the renal function, central nervous system, pancreas and other organs caused by thrombotic microangiopathy. The outbreak of HUS and bloody diarrhea associated with an infection of E. coli O104:H4, which took place in the European Union, the USA, and Canada, has resulted in 3,332 cases of STEC infection, 818 cases of HUS and 36 deaths in the period of May to June of 2011. Argentina is the country with the highest worldwide rate of HUS.

In Argentina, where HUS is endemic, between 300 and 500 new cases are diagnosed each year with an average annual incidence rate of one per 100,000 inhabitants. ${ }^{2}$ It is the leading cause of acute renal failure, and the second leading cause of chronic renal failure in children. Some studies show that Argentine cattle are the main reservoir of Stx-producing E. coli (STEC), with O157:H7 being the most frequent serotype. ${ }^{3}$ Although several virulence factors exist, the main one is Stx, which inhibits protein synthesis in the target cells. The risk of STEC infections becoming severe is related to the presence and amount of Stx 1 and Stx2. It is postulated that Stx penetrates the intestinal barrier and enters the systemic circulation. Even though no specific treatment for the syndrome has been developed to date, it has been shown that when E. coli $\mathrm{O} 157: \mathrm{H} 7$ is exposed to antibiotics, it can lead to increased phage propagation and the production of Stx. 
In the cases of Shiga toxin-producing diarrhea caused by E. coli, the use of antibiotics is connected with a greater frequency of HUS.

Current treatments for any diarrheal etiologies consist of replacing fluids and electrolytes by using oral or intravenous rehydration salts, zinc intake in malnourished children, and antibiotics in cases of bacteremia or severe infections. However, diarrhea remains a worrisome global disease $e^{4,5}$ and for this reason, advances in new treatments are especially valued.

\section{Review}

Bismuth hydroxide gel (BHG) is an active pharmaceutical ingredient with anti diarrheal and antisecretory action, and no inhibitory action on gastrointestinal motility. Several epidemiological studies confirm the efficacy of bismuth treatment for different types of $E$. coli, Salmonella spp., Shigella spp. and C. jejuni, for the treatment of acute diarrhea caused by rotavirus and enterotoxigenic $E$. coli in children, and as a supplement in the treatment of gastric and duodenal ulcers caused by Helicobacter pylori, among other applications. ${ }^{6-11}$ BHG has antibacterial activity at very low concentrations. Systemic absorption of bismuth is below $1 \%$, with a negligible rate of adverse effects.

Balagué et al., ${ }^{12,13}$ focused their research conducted at the Department of Bacteriology of the Faculty of Pharmacy and Biochemistry at the National University of Rosario (Argentina) on determining the effects of BHG (using the therapeutic concentration allowed in Argentina: $30 \mathrm{mg} / \mathrm{ml}$ ) on bacterial growth and the inhibition of pathogenicity factors of the most common organisms responsible for gastrointestinal infections.

The following results were presented by the researchers:

a. MIC of BHG of $6 \mathrm{mg} / \mathrm{ml}$ for Shiga-toxigenic E. coli, enteropathogenic E. coli, Salmonella typhymurium and Shigella flexneri. In the case of Klebsiella pneumoniae, the MIC determined was $10 \mathrm{mg} / \mathrm{ml}$.

b. MLC of BHG of $15 \mathrm{mg} / \mathrm{ml}$ for Shiga-toxigenic E. coli, enteropathogenic E. coli, S. typhymurium, Sh. flexneriand $K$. pneumoniae.

c. In the assay conducted for $C$. jejuni, the MLC determined was $0.03 \mathrm{mg} / \mathrm{ml}$

To determine the effect on the expression of different membrane pathogenicity factors, the line of research chosen by the research group at the National University of Rosario included determining the expression of flagella using mobility in optical microscopy, visualization of transmission using electronic microscopy, a hydrophobicity assay and determining the membrane proteins in order to evaluate the reaction on the bacterial surface.

The researchers' results showed an inhibitory effect of BHG in the expression of bacterial flagella and decreased fimbriated cells. Furthermore, a significant reduction in surface hydrophobicity was observed in the presence of BHG, which demonstrates a decrease in the expression and adhesiveness of bacterial fimbriae. Of special note in the same research paper was a $50 \%$ reduction in the expression of porins, proteins present in membrane, in the three strains tested: STEC EDL933, ARG4829 and ARG5468, in the presence of $1 \mathrm{mg}$ / $\mathrm{ml}$ of BHG.

Subils et al.,14 focused their research conducted at the Department of Bacteriology of the Faculty of Pharmacy and Biochemistry at the National University of Rosario (Argentina) on determining the effects of BHG on the replication of Stx933 phage encoded by Stx. The results reported by the researchers show a statistically significant decrease $(p<0.05)$ in the amount of phage title when exposed to BHG compared to untreated title. The decreased amount of phage produced reported was $90 \%$ for a dilution of the usual clinical dose of $1 / 3$ of BHG, which corresponds to a bismuth concentration of $10 \mathrm{mg} / \mathrm{ml}$.

To determine the influence of BHG on cytotoxicity mediated by Stx, the research paper was assessed by the team of Dr. Cristina Ibarra at the Physiopathology Laboratory (IFIBIO-CONICET) of the Faculty of Medicine at the National University of Buenos Aires. ${ }^{15,16}$ This study experimented on human colonic tissue in vitro pre-incubated with BHG and incubated with the STEC strain grown to the exponential phase.

The results obtained by Ibarra indicate that in the presence of STEC125/99, there was an inhibition of the net flow of water absorption which was completely prevented by the presence of 0.8 $\mathrm{mg} / \mathrm{ml}$ of BHG. A microscopic observation of tissues incubated with STEC125/99 showed a detachment of surface epithelium with subapical necrosis, whereas in the presence of BHG, only isolated areas of surface detachment were observed. The addition of $0.8 \mathrm{mg} / \mathrm{ml}$ of BHG to the mucosal side of the tissue significantly stimulated the flow of water absorption after 30 minutes incubation compared to the baseline absorption flow. The researchers concluded that Stx2 activity was significantly reduced when the BHG concentration was $0.8 \mathrm{mg} /$ ml. Cavalaro et al., ${ }^{17}$ studied the effects of different concentrations of BHG on the production of human rotavirus, which was conducted at the Department of Virology of the Faculty of Pharmacy and Biochemistry at the University of Buenos Aires (Argentina). The results of the research conducted by the group, show that BHG inhibits viral production by 99.97 and $99.8 \%$ with respect to controlling the virus when present in a dilution of the usual clinical doses of $1 / 5$ and $1 / 10$, respectively, in the incubation medium throughout the time of the viral infection. The EC50 value was determined as $0.0348 \mathrm{mg} / \mathrm{ml}$ (approximate dilution of $1 / 29$ ).

Padola et al., ${ }^{18}$ assessed the effect of BHG on STEC O26, O103 and $\mathrm{O} 157$, and observed a significant reduction in the number of colonies during the first 6 hours, except for STEC O145, which was not affected; this assessment was conducted at the Immunochemistry and Biotechnology Laboratory of Tandil Veterinary Research Center (CIVETAN), CONICET, CICPBA, at the Faculty of Veterinary Science.

\section{Discussion}

Bismuth compounds are effective in treating various diseases associated to gastrointestinal infections that can cause serious systemic complications. For this reason, the possible mechanisms of action will continue to be studied with renewed interest.

In the studies assessed, it can be seen that all the pathogens tested were sensitive to BHG. The MICs and MLCs described are below the clinical doses usually used. These results show us that BHG in clinical doses has a bacteriostatic and bactericidal effect on the most common microorganisms present in gastrointestinal infections. In this regard, eliminating the causative agent is one of the possible mechanisms of action of BHG as an anti diarrheal.

The virulence of strains is directly related to pathogenicity factors. A decreased expression should result in a lower infectivity of the 
pathogen. The studies of Balagué, Subils and Ibarra describe the inhibition of pathogenicity factors in contact with BHG.

The first event necessary for the gastrointestinal infection to be feasible is the ability of the pathogen to adhere to the epithelial walls. This review highlights the finding of a reduction in fimbriation, mobility and hydrophobicity at the cellular level produced by BHG, which avoids and prevents colonization and facilitates the ejection of pathogens outside the gastrointestinal tract, thus facilitating a smooth course in diarrheal manifestations.

Bacterial resistance, which is a serious public health problem, also depends on the expression of pathogenicity factors. In this regard, the finding of a decreased expression of membrane porins mediated by BHG gains significance. It can be inferred from the data published that BHG somehow affects the formation and/or function of surface structures.

The reduction produced by BHG inhibits bacterial resistance mediated by the bactericidal effects of the complement. For their part, Subils and Ibarra focused their research on the direct action of BHG on Stx. Stx damage the renal endothelial and tubular cells, which is considered an important virulence factor. Stx 1 and Stx 2 are encoded in the genome by lambdoid phage and release phage particles that infect other neighboring cells or remain in the environment as potential vehicles of virulence genes. The results of the BHG tests assessed on free bacteriophage are very encouraging, with reductions of 80 to $90 \%$ in the phage title. The deactivation of free bacteriophage caused by BHG could inhibit the spread of genes to other uninfected cells, which, in turn, would prevent the generation of new Stx-producing strains.

The analysis of the studies on the human colon shows that BHG inhibits the action of Stx on the epithelium. This action includes direct protection of colonic mucosa and inactivation of the bacterial factors responsible for producing Stx2. Therefore, it is highly likely that BHG can avoid the first events of disruption of the intestinal membrane and thus inhibit the course of the infection, which can cause hemolytic uremic syndrome in its most severe cases. The results obtained by Cavalaro et al. ${ }^{17}$ regarding the action of BHG on human rotavirus are also significant, as they demonstrate its ability to inhibit in vitro the replication of human rotavirus, which is the causal agent of a high percentage of diarrheas.

Padola et al., ${ }^{18}$ posed a complementary approach to the control of STEC infections by working with the bovine reservoir. Livestock are one of the main reserves of STEC, and carry these pathogens in their gastrointestinal tract, and then transfer them to the environment via feces. As a result, other animals and even vegetables for human consumption can become contaminated. The process of slaughtering livestock is another critical point for contamination. The gastrointestinal contents of infected animals can contaminate meat due to deficiencies in the process, and STEC can be incorporated into the food chain.

\section{Conclusion}

In sub therapeutic concentrations, BHG inhibits the growth of most intestinal pathogens, including human rotavirus. In vitro it affected three events intervening in the process of bacterial adhesion and colonization: fimbriation, bacterial mobility and surface hydrophobicity. BHG inhibits the action of Stx, deactivates phage encoded with Stx and protects the human colon against cytotoxicity.

\section{Acknowledgements}

None.

\section{Conflicts of interest}

Authors declare that there is no conflict of interest.

\section{Funding}

None.

\section{References}

1. Podewils LJ, Mintz ED, Nataro JP, et al. Acute, infectious diarrhea among children in developing countries. SeminPediatr Infect Dis. 2004;15(3):155-168.

2. Boletín Integrado de Vigilancia N294 SE3.Secretaría de promoción y programas sanitarios. Ministerio de la Salud. Presidencia de la Nación Argentina; 2016.

3. Rivas M, Miliwebsky E, Chinen I. The Case-Control. Study Group:Characterization and epidemiologic subtyping of Shiga toxin producing Escherichia coli strains isolated from hemolytic uremic syndrome and diarrhea cases in Argentina. Foodborne Pathog Dis. 2006;3:88-96.

4. Spizzirri FD, Rahman RC, Bibiloni N, et al. Childhood. Hemolytic Uremic Syndrome in Argentina:long-term follow-up and prognostic features. Pediatric Nephrology. 1997;11(2):156-160.

5. Afazani A, Beltramino D, Bruno ME, et al. Diarrea aguda en la infancia. Actualización sobre criterios diagnósticos y tratamiento. Consenso nacional SAP, Argentina; 2016

6. Dupont H, Helminger A, Heusser R, et al. Prevention of travelers diarrhea by the tablet form of bismuth subsalicylate. Antimicrob Agents Chemother. 1986; 29(4):625-627.

7. Lesa AME, Montrull HL, Nates SV, et al. Uso de un compuesto a base de gel de hidróxido de bismuto coloidal con pectina en la diarrea aguda. Medicina Infantil. 2004;11:180-184.

8. Bitsura JAM, De La Cabada FJ, Dupont HI, et al. Prevention of travelers diarrhea by the tablet formulation of bismuth subsalicylate. JAMA. 1987;257(10):1347-1350.

9. Avendaño P, Balm TK, Braun SD, et al. Bismuth subsalicylate in the treatment of acute diarrhea in children:a clinical study. Pediatrics. 1991;87(1):18-27.

10. Campos-Sánchez M, Eyzaguirre-Maccan E, Figueroa-Quintanilla D, et al. A controlled trial of bismuth subsalicylate in infants with acute watery diarrheal disease. $N$ Engl J Med. 1993;328(23):1653-1658.

11. Chowdhury HR, Faruque SM, Lescano AG, et al. The efficacy of bismuth subsalicylate in the treatment of acute diarrhea and the prevention of persistent diarrhea. Acta Paediatr. 2001;90(6):605-710.

12. Balagué C, Di Paolo J, Subils T.Efecto del hidróxido de bismuto sobre factores de patogenicidad de superficie de E. coli Shigatoxigénicas y otros virotipos. Cátedra de Bacteriología de la Facultad de Farmacia y Bioquímica, Argentina; 2013.

13. Di Paolo J, Subils T, Tomat D.Efecto del bismuto sobre estructuras de superficie y proteínas de membrana externa en cepas de Escherichia coli enteropatógena y Shigatoxigénica. XXXV CongresoChileno de Microbiología. La Serena. 2013.

14. Subils T, Casabonne C, Balagué C.The inhibitory effect of colloidal bismuth hydroxide gel on Escherichia coli O157:H7 and on the activity of Shiga toxins. BMC Research Notes. 2014;7:875. 
15. Massó M, García H, Gaguine L, et al. El gel de hidróxido de bismuto protege el colon humano de la acción patogénica de E. ColiO157:H7 productor de toxina Shiga tipo 2. Physiological mini reviews. 2014;7:132.

16. Massó M, García H, Zotta E, et al. Bismuth hydroxide gel prevents human colon from cytotoxic action induced by EHEC. 9th International Symposium on Shiga Toxin-Producing Escherichia coli Infections, Boston, USA; 2015
17. Cavallaro L.Producción de rotavirus humano en presencia de gel de hidróxido de bismuto. Cátedra de Virología, Facultad de Farmacia y Bioquímica, Argentina; 2006.

18. Etcheverría A, Arroyo GH, Gaguine L.Effect of bismuth hydroxide gel on Verocytotoxin-producing Escherichia coli. 9th International Symposium On Shiga Toxin (Verocytotoxin)-Producing Escherichia coli Infections, Boston, USA; 2015. 